\title{
Research on 'One-Map’ Mineral Resource Management Information System (MRMIS) of China
}

\author{
Wang Li-fang ${ }^{1}$, Wu Xiang-bin ${ }^{1}$, Cao Hui ${ }^{2}$, Zhang Bao-yi ${ }^{1}$ \\ ${ }^{1}$ MOE Key Laboratory of Metallogenic Prediction of Nonferrous Metals, School of Geosciences and \\ Info-Physics, Central South University, Changsha 410083, China; \\ ${ }^{2}$ Modern Education Technology Center, Henan Radio and Television University, Zhengzhou \\ 450008, China
}

\begin{abstract}
Keywords: 'one-map'; mineral resource management (MRM); information system; mining rights; e-government
\end{abstract}

\begin{abstract}
Based on the results of national mining rights on-the-spot survey and related foundation and business database, the general idea and the tech-framework of 'one-map' mineral resource management information system (MRMIS) was studied through comprehensively and systematically analysis of mineral resources administration's present status, business processes and the demands in the future. The 'one-map' should not only be a comprehensive map, but also a 'relation graph' that would reflect the businesses' relations, and workflow driving approach should be used to realize organic interconnection of each business in 'one-map'. The national, provincial, municipal and county four levels MRM interconnecting network was designed on the basis of $\mathrm{C} / \mathrm{S}, \mathrm{B} / \mathrm{S}$ and $\mathrm{M} / \mathrm{S}$ hybrid software architecture, and the integrated tech-framework of effective supervision for mineral resources administration and information services for the public was achieved.
\end{abstract}

\section{Introduction}

Large increases in human population and economic growth during the twentieth century placed a huge stress on Chinese mineral resources, whereas mineral resources are non-renewable. Therefore, the State Council of the People's Republic of China developed and harmonized several common policies, laws, and strategies for access to and exploitation of mineral resources for the socio-economic development of the community. In February 1998, 'Regulation for Registering to Explore for Mineral Resources Using the Block System', 'Regulation for Registering to Mine Mineral Resources', and 'Regulation for Transferring Exploration Rights and Mining Rights' were successively promulgated and implemented in China. To minimize impacts to the environment while providing a climate that encourages economic growth, mineral resource management is responsible for the policies and implementation of programs which regulate or impact mineral extraction.

The mineral resource management information system (MRMIS) applies suitable information technology as a tool to help increase efficiency of geological and mineral resource management - data acquisition, storage, processing and dissemination. The roles of information systems in mineral resource management mainly include: (i) The MRMIS is the collection, flow, integrity and management of information along the value chain of mineral resource management (MRM). The MRMIS considers the mine-based disciplines of survey, evaluation, planning, geology, geochemistry, geophysics, hydro-geology, remote sensing (RS) and other relevant ones as a single entity rather than as discrete functional domains, and has a critical role to play within environmental sound and profitable mining ${ }^{[1]}$, which can be used in mineral resources assessment ${ }^{[2]}$, distribution analysis of mineralization $^{[3]}$ and mining safety monitoring ${ }^{[4]}$. For example, the U.S. Geological Survey (USGS) has already started to use GIS to carry on the managements to the ownerships, the mines species and the geographical positions of the surface and underground mineral resources, and has taken it as the important reference for the mineral resources developing and planning. (ii) The MRMIS provides the governmental and private sectors with the geological and mineral resource information, and establishes the information network and e-government with department of mineral resource and among the concerned organizations, which can be used in damage risk assessment on mining 
terrains $^{[5,6]}$, dynamic monitoring of ecological environment ${ }^{[7]}$, and sustainable development strategic evaluation of mineral resources ${ }^{[8,9]}$. For examples, Australian Mine Foundation (AMF) has already established the idea of providing geo-information services in the nationwide scope, and Institute of Geology \& Mineral Exploration (IGME) in Greek has collected geology, geochemistry, geophysics, geology, hydro-geology, satellite data and other relevant information to provide information consulting services for the mining planning and environment protection. (iii) The MRMIS provides mining rights' management with online examination and approval, registration, mining right's evaluation ${ }^{[10,11]}$, secondary e-commerce market management ${ }^{[12]}$ and other functions, taking the online e-government systems of British Columbia and Quebec in Canada as examples. An and Cui (2008) designed a mining right's transaction information service system which is on the basis of the vertical structure of network to provide Integrated Service Planning and Execution (ISP\&E) ${ }^{[13]}$. The interactions of MRMIS should be standardized, institutionalized and regularized.

The project of 'one-map' land management has carried on by the Ministry of Land and Resources (MLR) of China for three years, and has achieved excellent results, which is satisfied from central to local governments ${ }^{[14]}$. How to extend the experiences of 'one-map' land management into mineral resource management has been a question worthy of consideration. According to the deployment of MLR, the application in demonstrating of the databases of on-the-spot mining right survey has been carried out in Hubei, Fujian, Nanchuan of Chongqing, Luoyang of Henan, Ganzhou of Jiangxi, Heihe of Heilongjiang, Hebei and Shandong, and the basic framework and functions of 'one-map' of MRMIS come more into focus ${ }^{[15]}$. It makes a creative exploration for the future 'one-map' MRMIS to meet the demands of different levels of land and resources management departments. The Ministry of Land and Resources of China has also carried out remote sensing monitoring on key mining areas and gradually executed the 'one-map' comprehensive mineral resources law enforcement to realize the overall objectives of 'one-map' MRMIS in the future.

The purpose of 'one-map' MRMIS is to achieve that all the businesses of MRM to be completed in a set of standardized geographical data and unified spatial reference system, which requires the data formats, technical norms and service standards to establish the unified essential data. The mineral resource administration by 'one-map' is a comprehensive measure adopted by the center and local government to achieve the precision, normalization and standardization of mineral resources administration, which beneficially achieve the coordination and optimization of administrative approval of all aspects of businesses of MRM departments. It needs the innovations of the institutions and patterns of MRM, and needs to establish national, provincial, state and county four levels computer network, and the mechanism of data updating, operation and maintenance. In summary, the mineral resource administration by 'one-map' emphasizes the character of "management", that is to say, it emphasizes to use a map to carry on the dynamic supervision of mineral resources administration. Through the advanced 3S technology, MRMIS serves the mineral resources administrative inspection of and supervision over law enforcement.

\section{Mining rights survey and mrm by 'one-map'}

The foundation of mineral resource administration is the completion, factuality and reliability of mining rights' basic data. However, because Chinese mining industries have different management requirements and regulations in different historical periods, it appears that the mining rights of some areas are cross overlapping, and the data in the registration database of mining rights have the mistakes, omissions and repetitions. The unreliable data seriously affect the MLR to implement the responsibility of reasonable protection and utilization of mineral resources. Therefore the Ministry of Land and Resources of China launched the on-the-spot survey of national mining rights in 2007 . The on-the-spot survey of national mining rights is under the unified leadership of the MLR according to the requirements of 'unified organizations, methodology, standards and progresses'. It aims to carry out the on-the-spot surveys to the present status of nationwide mining rights (excluding oil, natural gas and coal bed gas), to approve the effective scopes of mining rights, and to find out the present status and distributions of mining rights, to timely correct the problems which are found in survey, to gradually update the registry database of mining rights, and to improve the management level of 
mining rights ${ }^{[15]}$. All provinces' invests are more than 2.3 billions yuan for the on-the-spot survey of national mining rights, and technical personnel reaches more than 28 thousands. By the end of 2009, it altogether has completed nearly 150 thousands mining rights' on-the-spot surveys (including 111 thousands mining rights and 36 thousands exploration rights), and has formed a set of mineral exploration engineering distribution map, the provincial distribution map of mining rights, and other basic data. After completion the on-the-spot survey of mining rights, it has entered the stage of data compilation and achievements' summary since 2010. The achievements obtained by the mining right's survey will be an important foundation of the project of MRM by 'one-map'.

The achievements of mining rights' survey can not only be used in the registration treatment and alteration of the problems found, but also be applied in the planning and organizing of mineral exploration and development, the dynamic supervision of mineral reserves, the daily management of mining rights and the like, especially promoting the construction of the MRMIS of 'one-map', which improves the utilization levels of the achievements of mining rights' on-the-spot survey. Loading the mining rights' survey data into the platform of MLR's daily supervision of 'one-map' mineral resources administration directly, the achievements of mining rights' on-the-spot survey will be applied comprehensively.

\section{General idea FOR MRM by 'one-map'}

Based on the national, provincial, municipal and county four levels mining rights' survey spatial databases and GIS technology, unifiedly integrating the daily mine development supervision data, geographical maps and other mine-related large scale maps, the MRMIS of 'one-map' pattern is being developed to satisfy the MRM needs of basic data statistics, analysis and cartography and so on. In the principle of taking the databases of mining rights' survey as the foundation, the governmental units as the architecture and mineral resources administration as the goal, the national, provincial, municipal and country four levels network is constructing. In accordance with the overall thoughts of the pilots advanced, partial executing, unified platform, orderly expansion, standard specification and dynamic updating, the project of 'one-map' MRMIS will realize the convenient operation, precise management and efficient applications of mineral resources administration, as shown in figure 1 . In summary, the MRM by 'one-map' mainly includes the following several aspects.

'One-map' mode management and sharing of the data of mining rights' survey.The mining rights' approval, registration and various transactions (including completely or partial transferring, share right's transaction, indirect financing and so on) belong to the behaviors which need to obtain the governments' permission. Using GIS technology, the different channels, times, and professional data (including the information of exploration, exploitation, reserves, planning and mining rights and so on) are integrated on the 'one-map' mineral resources administration platform, which provides various functions and services of supervision, approval and statistics related to administrative operations of mineral resources and promotes the scientization and refinement of mineral resources administration. 


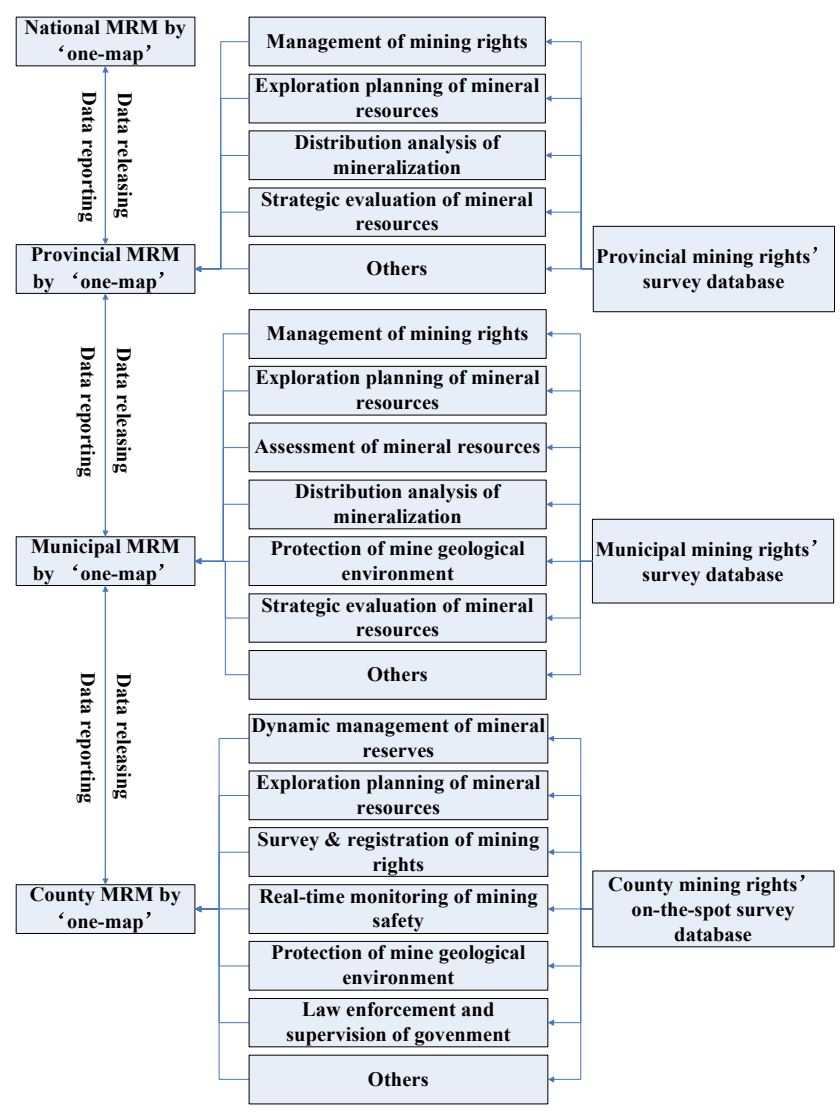

Figure 1. Logic graph of MRM longitudinal and transverse business.

'One-map' dynamic supervision of mining activities and mine environment. The most realistic and urgent task of strengthening mineral resources administration is that strengthens the law enforcement from disorder to order and further from order to science and creates a good environment for mining economy to achieve the purpose of reasonable protection and utilization of mineral resources $^{[16]}$. The China Geological Survey (CGS) carries on multi-objective remote sensing investigation and supervision to the hot spots and problems areas of mineral resources development concerned by the public ${ }^{[17]}$. The local governments execute the on-the-spot surveying according to remote sensing monitoring data, investigating the illegal activities according to the laws and regulations, implementing the corrective and remedial measures, effectively fighting the illegal exploitation, and controlling and maintaining the order of MRM. As the palm platform of 'one-map' MRMIS, the GPS/PDA handset technology is used to establish digital field supervision platform to gain the objective basic data, establish the data updating mechanism of mining rights' on-the-spot survey, maintain the order of mining industry and improve the mine environment comprehensively.

MRM's information sharing platform of national, provincial, municipal and county four levels network. The MRMIS of national, provincial, municipal and country four levels network forms the mineral resources administration operation system of 'looking up from the sky, surveying from the ground and treating from the network' to achieve the mineral resources' efficient configuration and whole supervision. According to the actual requirement of MRM by 'one-map', it should include the longitudinal and transverse two levels of contents. On the longitudinal level, it compiles and reports the data from the counties, cities, provinces and MLR progressively to realize the consistency of four levels data; on the transverse level, it takes the basic map as the foundation and integrates various topics maps of mineral resources administration to achieve MRM with a series of standards and data. Based on the various achievements of mining rights' on-the-spot survey and concerned about each important sector of mineral resources administration and characteristics of multi-level networking, the consistent technical line is adopted to establish the application system which can meet the MRM departments' requirements of various businesses to ensure the unified using of the mining rights' data and other related thematic map, and unified data standard and in/out interface are used to achieve the exchanges of county, municipal, provincial and national four levels' data. 
'One-map' mining rights' evaluation.As the state is the only subject of the ownership of mineral resources in China, the mining right is the using right of mineral resources, and the subjects of mining right are natural, legal persons and other economic organizations. If the nation remises the mining right, it would have the possibilities of the loss of the state-owned assets. The mining right's dispute usually involves the vital interests of the two parts, and it needs to provide the mining right's evaluation with certain approval. This kind of mining right's evaluation should be carried on by the commission of government administrative subject. The 'one-map' MRMIS realizes the intervention of geologists, mining engineers, metallurgy engineers, environment engineers, mining economists, legal professions, geophysicists, geochemists prospecting etc. many subjects' specialists to make the evaluation with higher preciseness, rationality and credibility.

Planning of mineral resources exploration and development based on 'one-map' MRM.Adopting of GIS software, data mining, mapping and cartography, the 'one-map' MRMIS forms various reports with excellent maps, pictures, charts and texts, and draws up mining-related maps to summarize and analyze the mining rights' distribution characteristics. Based on the comprehensive analysis, it combs the problems existing in the setup and management of exploration right and mining right in China, and reveals the causes of producing these problems to put forward the rational proposals and countermeasures. The obtained incomes of mineral resources' compensation, the mining rights' fees and the sale prices of mining rights and so on, are divided by national and provincial finance. In accordance with the principle of taking from the mining and using in the mining, the incomes should be used in the key mineral types and key metallogenic areas in the plan of national and provincial economic and social development. The 'one-map' MRMIS organizes the exploration, development and planning of mineral resources scientifically, and provides technical support and decision-making basis to maintain the sustainable development and utilization of mineral resources.

\section{Tech-framework OF 'one-map' MRM}

The 'one-map' MRMIS is an important part of information infrastructure construction of China, which will significantly enhance the levels of mineral resources exploration, information sharing development and utilization. The implementation of 'one-map' MRM can be divided into the following levels: Firstly, to research and analysis goals and task requirements of 'one-map' mineral resources administration to design the four levels network of the national, provincial, municipal and county; secondly, to establish the mining rights' on-the-spot survey database, software systems; finally, to study the data standards supporting system and technical specifications, network architecture, security organization and so on. The 'one-map' MRMIS is very complex system engineering, concerning knowledge of mineral resources administration businesses, spatial database, software development, computer network and many other technical fields. Specifically, the main study contents of 'one-map' MRMIS are as followings (as shown in figure 2):

(i) On the basis of comprehensively analysis the current situation and business process of mineral resources administration, the perfect data standards and data exchange and sharing mechanisms are made. Providing a unified mineral resources administration submitting, issue data format, the consistency of statistical data in various ways is ensured. The MRM mode and processes should be innovated and optimized in accordance with the requirements of 'one-map' mineral resources administration.

(ii) Relying on e-government virtual private network (VPN), four levels MRM interconnection of national, provincial, municipal and county is realized. Using the advanced large-scale database systems, GIS technology, network technology and other information technology, the data center is constructed to achieve mineral resources administration's data collection, management, sharing, remote access and linkage operation, the upper and lower linkage and timely updated mechnisms of mining rights' survey database are established. The mining rights' on-the-spot survey data and the real-time accessed information of national mining activities supervision are combined on 'one-map' to analyze and investigate the national mining rights in different regions, types and scales, and to 
summarizes distribution regularity and problems of mining rights setting. Thus the necessary policies on mineral resources exploration and macro-control on mining activities are carried on to create a healthy natural and social environment for the mining industries.

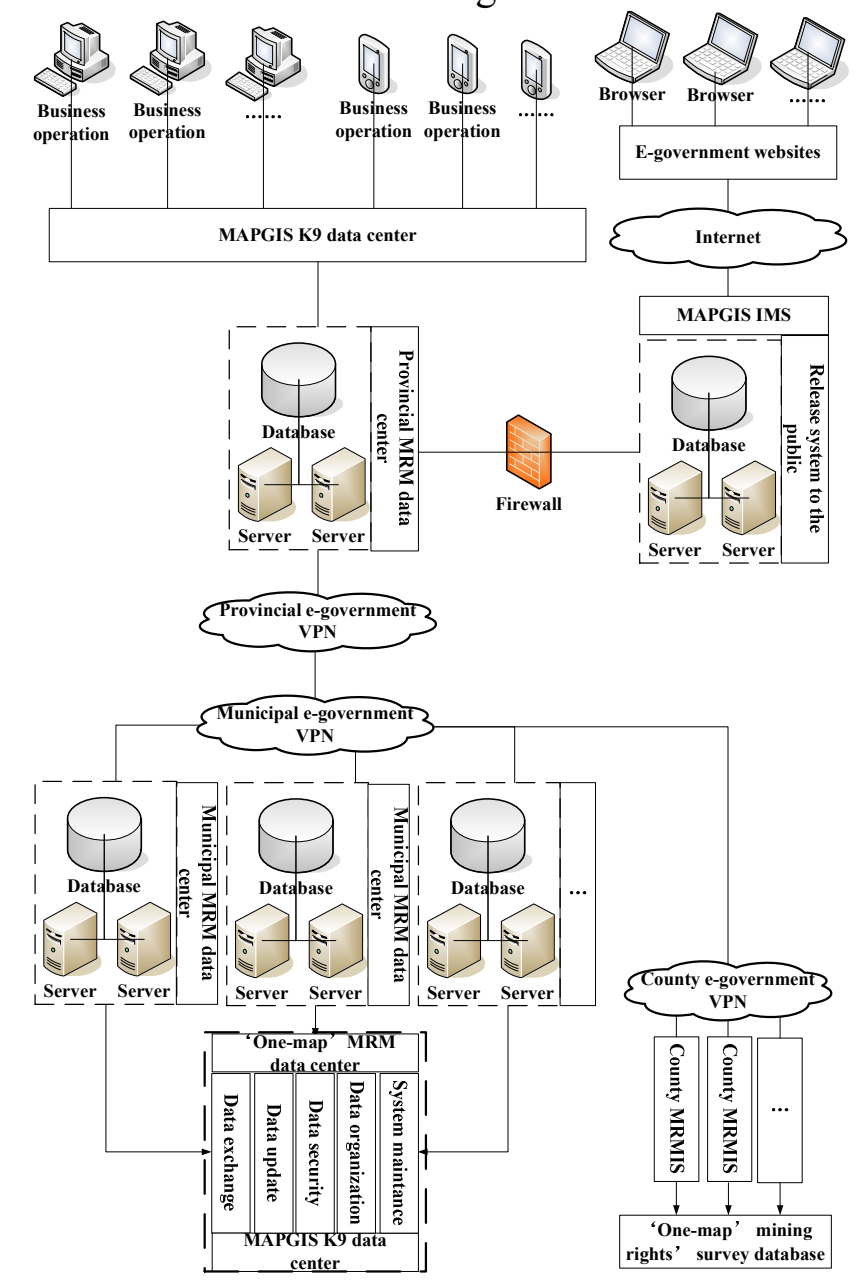

Figure 2. Graph of general tech-framework of MRM by 'one-map'

(iii) The workflow drived 'one-map' mineral resouces administration business logic graph is designed. On the basis of information sharing, the provincial MRMISs by 'one-map' are established. The 'one-map' is not only a comprehensive map but also much more important to provide a 'relation graph' that reflects business relationship, that is, a relation graph covering every business branch in MRM. Drived by the workflow, compilation of exploration planning of mineral resources, dynamic management of mineral reserves, registration of mining rights, updating and maintenance of mining rights' database, expropriation of mineral resources compensation charges, law enforcement supervision of mining activities and mine environmental, mining rights evaluation and information services and other core business processes are related in the 'relation graph' as the main line. All the details of mining activities can be following feedback through the graph to ensure the realization of information sharing and a unified call among the all businesses, which avoids confusion and confliction caused by the data inconsistencies. The MRMIS improves the authority and precision of the mineral resouces administration, providing a strong support for dynamic supervision and decision-making of MRM.

(iv) Through the combination of remote sensing satellite interpretation, on-the-spot survey of hand-hold PDA and other techniques, the mining activities' real time, dynamic monitoring system is established to achieve the scientific, rational exploitation and effective protection of mineral resources, to reduce environmental degradation caused by mining activities at the minimum. The MRMIS makes the mineral resources administration scientific, standardized and legalized gradually to support national economy and social development. 
(v) Role-based "one-map" mineral resouces administration security and privacy management is applied. The security and confidentiality management on the 'one-map' and overlapped thematic data sets the appropriate view, query, using permissions for different roles according to different deparments, levels and business processes. The 'one-map' MRM data information services for all levels and functional departments are established. All departments can query their own basic data and core data, also may be authorized to view an open thematic data of other departments.

(vi) The internet technology is used to build metadata release system, which provides the public with the information services. According to the need of MRM's businesses, the MRMIS is subdivied into information consulting services, MRM daily business treatment, ont-the-spot handheld PDA suvey, planning and decision-making supporting and other subsystems. Each subsystems' software architectures adopt hybrid structures of browser/server, client/server and mobile/server to achieve the separation of data, logic businesses and client operation terminal.

\section{Conclusion}

On the basis of national mining rights' on-the-spot survey database, the national MRMIS is establishing through the technology of GIS and large databases, which necessarily further standardizes mining industries' management and improves government services. This paper proposed the general idea and the tech-framework of MRM by 'one-map' based on a comprehensive, systematic analysis of MRM's status, business processes and future needs. The main obtained results are as follows:

(i) The 'one-map' is not only a comprehensive map, but also 'relation graph', which reflects the business relationship of MRM. In order to archive organic integrating of all business in 'one-map', the workflow driving approach should be adopted to realize information sharing and unified call of MRM's inter businesses.

(ii) The 'one-map' MRM is divided into vertical and horizontal two levels, based on the national, provincial, municipal and county four levels interconnection network which has the $\mathrm{C} / \mathrm{S}, \mathrm{B} / \mathrm{S}$ and $\mathrm{M} / \mathrm{S}$ hybrid software architecture. Through unified data standards and the i/o interface, the county, municipal, provincial, national four levles' data exchange is realized.

(iii) By the means of GIS, remote sensing, hand-hold PDA/GPS, spatial databases, the internet and other techniques, the 'one-map' MRM is introduced to form a 'view in the sky, survey on the ground, management on the internet' MRMIS, so that mineral resources administration will become more scientific, standardized and legalized.

\section{Acknowledgment}

We would like to thank MOE GIS software and its application engineering center and Central South University co-building 'MAPGIS laboratory' for providing the MAPGIS software.

\section{References}

[1] McGill J E. Technical risk assessment techniques in Mineral Resource Management with special reference to the junior and small-scale mining sectors[D]. Pretoria: University of Pretoria, 2005.

[2] Zhang B, Mao X, Zhou S, Wang F, Zeng W, Yan F,Deng J. The design and implement of prediction and assessment database for mineral resources - take manganese ore in the western Guangxi and southeastern Yunnan, China as an example[J]. Geology and Exploration, 2009, 45(6): 697-703.

[3] Penney S R, Allen R M, Harrisson S, Lees T C, Murphy F C,Norman A R. The global distribution of zinc mineralisation, an analysis based on a new zinc deposits database[J]. Transactions of the Institutions of Mining and Metallurgy, Section B: Applied Earth Science, 2004, 113(3): B171-B182. 
[4] Salap S, Karslioglu M O,Demirel N. Development of a GIS-based monitoring and management system for underground coal mining safety[J]. International Journal of Coal Geology, 2009, 80(2): 105-112.

[5] Malinowska A,Hejmanowski R. Building damage risk assessment on mining terrains in Poland with GIS application[J]. International Journal of Rock Mechanics and Mining Sciences, 2010, 47(2): 238-245.

[6] Mancini F, Stecchi F, Gabbianelli G. GIS-based assessment of risk due to salt mining activities at Tuzla (Bosnia and Herzegovina)[J]. Engineering Geology, 2009, 109(3-4): 170-182.

[7] Qiao Y, Zhao S,Fang Y. Dynamic monitoring of ecological environment based on advanced information technology[C]. 2010 International Conference on Computer Application and System Modeling (ICCASM'2010). Taiyuan, China, 2010, 194-198.

[8] Xiang J-Y. Strategic selection of sustainable development of mineral resources in China's mining cities[C]. Proceedings of the International Conference on E-Business and E-Government (ICEE'2010). Guangzhou, China, 2010, 812-815.

[9] Li J. The system study of the strategic evaluation of mineral resouces[D]. Wuhan: China University of Geosciences, 2004.

[10] Wang C. The evaluation studies of mining right's market and value[D]. Kunming: Kunming University of Science and Technology, 2003.

[11]Guo J. Research on system of mineral right evaluation[D]. Beijing: China University of Geosciences, 2006.

[12] Ma Y, Tian J,Wang H. The management about the secondary market of mineral rights based on E-government[C]. Proceedings of the International Conference on E-Business and E-Government (ICEE'2010). Guangzhou, China, 2010, 865-868.

[13]An H,Cui N. Web-based Vertical Information Services for Mining Right Trade[C]. The IEEE International Conference on Industrial Informatics. DCC, Daejeon, Korea, 2008, 786-790.

[14]Zhao J, Zhao Q,Zhao S. Discussion on theory and technical issues of 'one-map' new mode Land Management[C]. 2009 The Annual Conference of China Land Association. Yangzhou, China, 2009, 847-857.

[15]Mineral Resources Development Administration Division of MLR, Development Research Centre of CGS. The working guidelines and technical requirements of national mining rights' on-the-spot survey[M], Beijing: China Land Press, 2008.

[16]Bai Y. Impovement of mineral resouces mangement to promote sustainable economic development of mining industies[J]. Geology in China, 1999, 26(4): 9-10,8.

[17]CGS. The working guidelines and technical requirements of mine remote sensing monitoring[M]. Beijing: China Land Press, 2009. 